Homayoun Khoshravan

Head of Caspian Sea National Research \& Study Center, Water Research Institute, 8

Km of Khazarabad Road, Sari, Mazandaran, Iran; e-mail: h_khoshravan@yahoo.com

\title{
MIANKALEH TERRITORIES RESPONSE TO CASPIAN CATASTROPHIC FLUCTUATION
}

\begin{abstract}
The main objective of this study is Miankaleh shoreline displacement against Caspian rapid sea level changing and anthropogenic impact. The morphological subunits and shoreline position have been recognized by comparing and processing of aerial photos related to 2 periods of expanded Caspian Sea level fluctuation (1966-2005). Then observational works and surface geology have been done along the eight transects from extremity of western to eastern of mentioned area. Main results show the tendency of flooding vulnerability and shoreline displacement increase at the end of eastern region of Miankaleh near Ashooradeh peninsula where there is an interaction with Caspian rapid sea level changing. In the direction of west, shoreline deformation degree declines gradually.
\end{abstract}

KEY WORDS: Caspian; beach; fluctuation; Miankaleh

\section{INTRODUCTION}

The susceptibility of coastal lowlands, which affected by climatic process, water level changing of oceans and seas and impacts of anthropogenic activities, is very high. So that the ecological and morphodynamic characteristics of these regions become involved in a critical vulnerability due to the function of sea water level rise and down periods. In fact, slight slope of lands behind coast which have negative and reverse direction as compared with coastal berms, provide favorable conditions for marining on the occasion of water level rise and coastal aquifers piezometric level rise. Consequently, marginal wetlands appear. In view of biodiversity in these areas, habitat value and significance for conservation objectives is strongly considerable. Miankaleh wetland has such environmental importance so that according to the defined criteria by international union for conservation of wetlands has presented as a protective area. The connection of this basin and Caspian Sea is established via marginal canals. Usually in the case of water level rise, vast parts of littoral zones could be submerged then territory of Miankaleh wetland will expand. The main question of this study is the impact assessment of natural and anthropogenic factors on morphodynamic deformation in Miankaleh lowland area. Environmental and erosive vulnerability conditions of this area have increased because of Low and reverse slope sandy shore, Caspian rapid sea level changing and hydrodynamic forces from it, furthermore economical efforts expansion (fishery, port, oil and gas, tourism, power plant and construction).

The results of several surveys prove that this coastal significant area of Caspian Sea has permanently been impressed by environmental forces of Caspian Sea level changing throughout the Quaternary geological history [Khoshravan, 1995]. Hence current morphological appearance is depended on hydrodynamic forces and Caspian Sea water fluctuations [Khoshravan, 2000]. With the comparing the shoreline transpositions of Caspian Sea south- eastern coastal parts on the region between Torkaman and Gomishan ports in 40 recent 
years, we can find out the replacement rate and morphological deformation of Caspian Sea slight slope coasts along with rapid fluctuating periods [Khoshravan, 2002]. Furthermore, it is proven that the wide sandy area evolved from flows parallel with coast in direction of west to the east throughout recent several thousand years [Kosari, 1995]. Survey about native and immigrant bird biodiversity of mentioned wetland in addition to the benthic and fishes, show precious habitat value and excessive bio susceptibility of this area [Kosari, 1995].

Recent accumulation of trading and commercial efforts in ports, water effluents from city and village communities and leading industries, solid waste disposal, toxicant concentrations generated from fertilizers and pesticides, is the main cause of increasing environmental vulnerability rate around Gorgan bay and Miankaleh wetland [Moghadam, 2004]. Therefore, this study aims to assessment of shoreline morphodynamic deformation which effected by rapid sea level changing and human activities in Miankaleh peninsula. To achieve this main goal, we have simulated the structural reaction encounter with the mentioned agents by taking advantages of aerial photos processing and field observations.

\section{STUDIED AREA, MATERIALS AND METHODS}

The slight slope and lowland, Miankaleh is located on the south - eastern regions of the southern coasts of Caspian Sea in the lengthwise direction around a canal between Torkaman port and Ashoradeh peninsula where is adjacent to the Amirabad port (Fig. 1). It is situated in the widthwise direction between Gorgan bay and Caspian Sea. This area is expanded as a sandy spit in the direction of western, eastern along with the Caspian Sea shoreline. The length is about 70 kilometers and the width is about 2 kilometers. There is one of the most important Caspian Sea ports (Amirabad port) in the western parts of this region. Also Ashoradeh peninsula, in the end of eastern parts, is considered as a main center for the sturgeons fishing. The aqueous connection of the Gorgan bay and Caspian Sea is feasible via marginal canals such as Ashoradeh and Khozeini canal. The vast regions of Miankaleh area is covered by maritime sandy sediments which appear in the intercalation shape of the microlithic and adhesive wetland sediments. This kind of sediments is seen in central parts of peninsula that contains lots of mussels. Also, the eastern parts of Miankaleh include sedimentary wetland environment and middle part where is concentrating location for the majority of the aquatic organism.

After collecting required data, morphologic features and widespread morphodynamic phenomena conditions of this area were assessed with applying of satellite images during the time between 1965 till 2005. Morphological subunits of the area in the direction of vertical to shoreline between Gorgan bay and Caspian Sea was measured by field works conducted around eight transects where it was chosen in lengthwise direction of Miankaleh. Shorelines position around peninsulawasassigned by transferring data to the geological information system (GIS) and putting down them on digitized map. The transpositions of shoreline and submergence of coastal lands were verified by Interpreting and comparing of aerial photos belonged to a 40 years period of times (1965-2005) in a scale of 1:10000 which contains both water level rise and down conditions. After that, we achieved to identify vulnerable regions towards Caspian rapid sea level fluctuations.

\section{RESULTS}

\section{Miankaleh morphological subunits}

The aerial photos processing and field works conducting around eight measurements transects (Fig. 1) specify that Miankaleh territory possess several morphological subunits and sedimentary sub-environments in the direction of west to east (Table 1). 


\section{Shorelines transposition}

The consequences of processing and comparing the aerial photos of Miankaleh coastal regions in a period of times (19652005) which contained Caspian Sea water level rise and down phenomena, show different dislocation of Miankaleh peninsula shorelines in western, central and eastern parts (Fig. 2). The scope of the coastal lands submergence in the situation of water level rise has diverse features in the different regions. Besides the extension of coastal morphodynamic features such as: erosive bays, connecting canals, wetlands and sandy spit expansion happen more in the case of

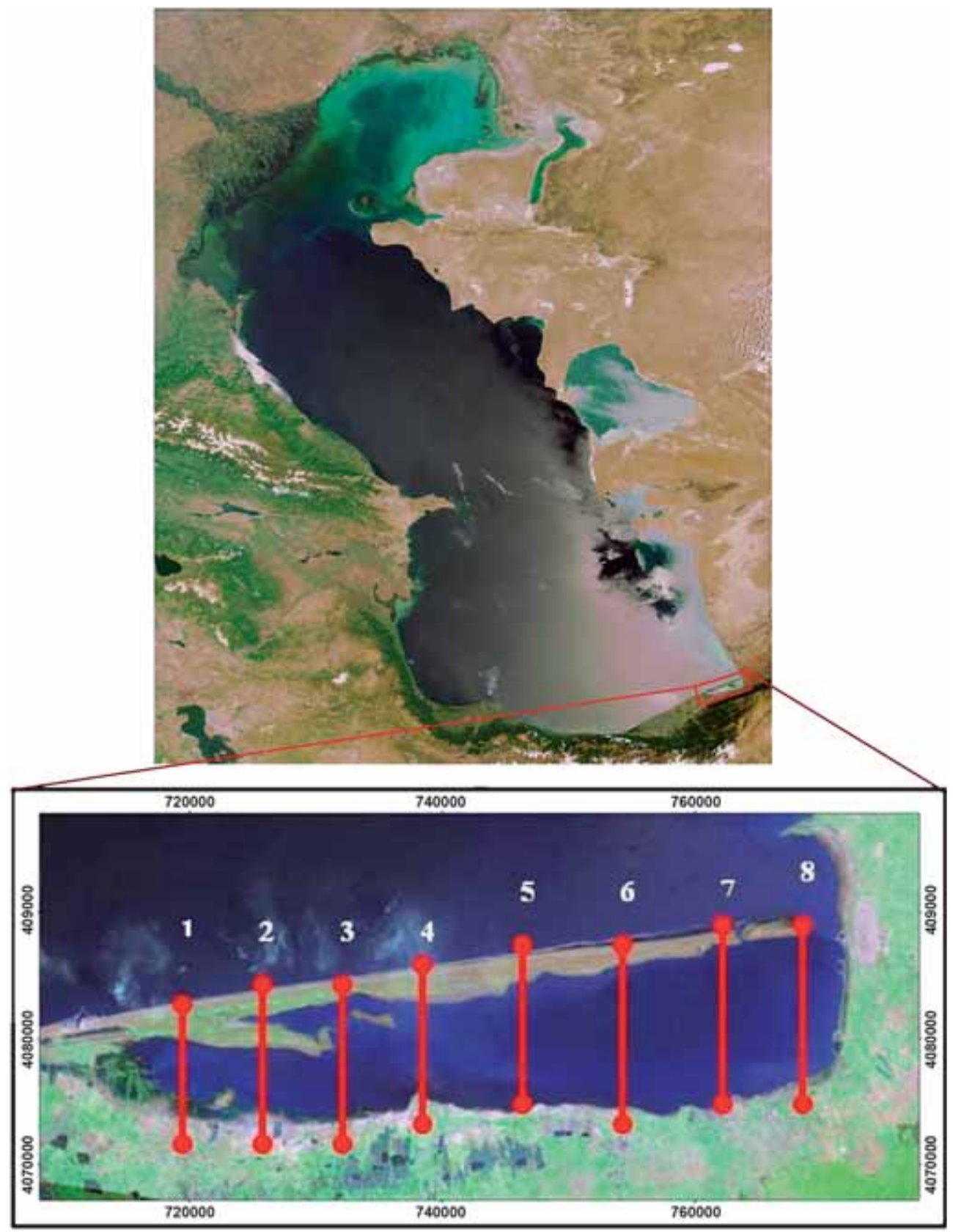

Fig. 1. Studied area location map 
Table 1. Sedimentary environments and morphological subunits of Miankaleh territory

\begin{tabular}{|c|c|c|}
\hline Miankaleh Region & Sedimentary sb-environments & Morphodynamic Phenomena \\
\hline Western Part & $\begin{array}{l}\text { Aeolian environments, } \\
\text { Primitive Berms, } \\
\text { Wetland Fringe, } \\
\text { Shoreline, } \\
\text { Wetland Band Beam, } \\
\text { Gorgan Bay }\end{array}$ & $\begin{array}{c}\text { Erosive terraces, } \\
\text { Beach cusps, } \\
\text { Sand Dunes, } \\
\text { Primitive beach and Fluctuation } \\
\text { terraces }\end{array}$ \\
\hline Central Part & $\begin{array}{c}\text { Shoreline, Wetland, } \\
\text { Sand Dunes, marginal canals, } \\
\text { Wetland Fringe, } \\
\text { Gorgan Bay }\end{array}$ & $\begin{array}{l}\text { Beach cusps, } \\
\text { Ripple marks, } \\
\text { Scattered Sand Dunes, } \\
\text { Strip Pool Pits, } \\
\text { Sand Spits }\end{array}$ \\
\hline Eastern Part & $\begin{array}{l}\text { Marginal lagoon, Primitive Sandy } \\
\text { beach, Gorgan Bay }\end{array}$ & $\begin{array}{l}\text { Pool Pits, } \\
\text { Lagoon }\end{array}$ \\
\hline
\end{tabular}

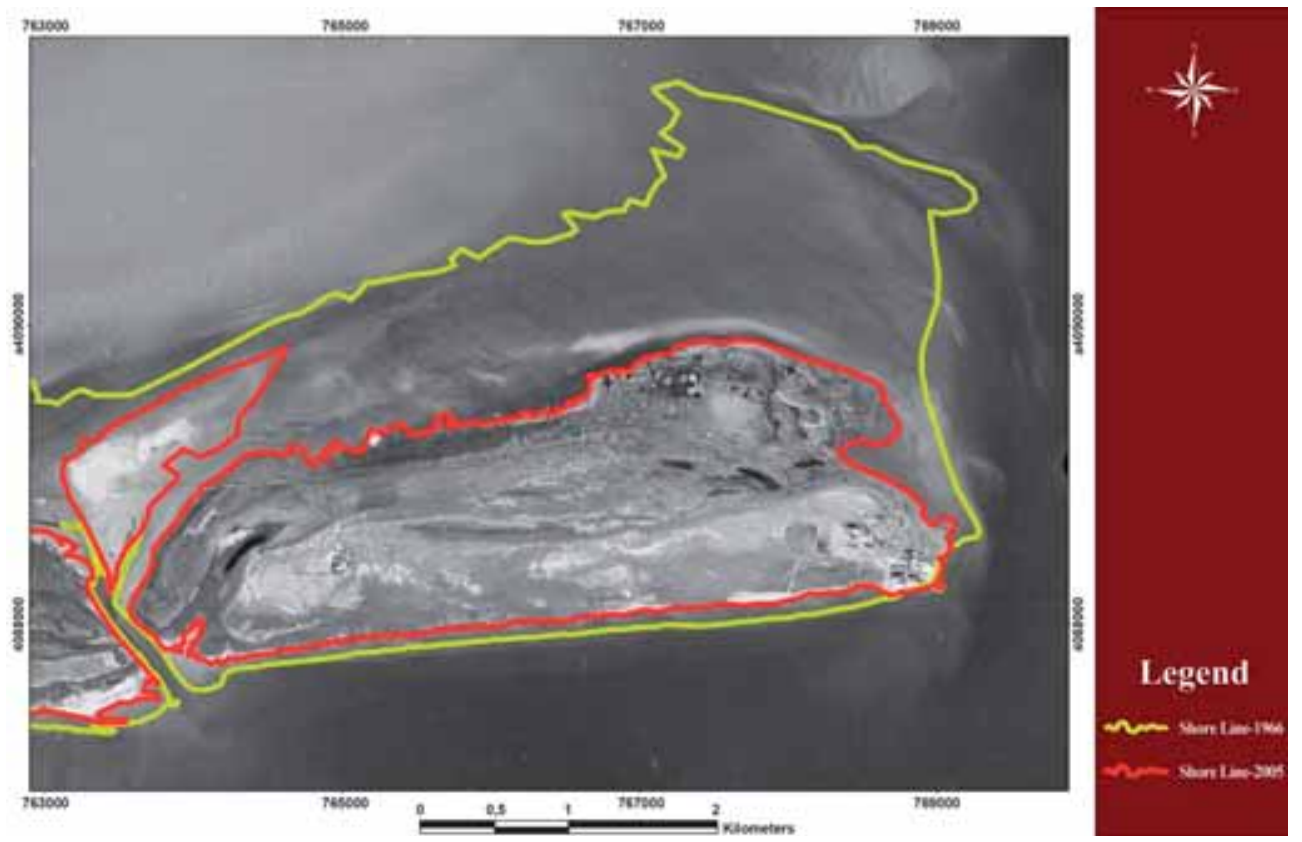

Fig. 2. Shoreline displacement along the eastern part of Miankaleh

sea water level rise to sea water level down. In the time of Sea transgression period, the growth of vegetable coverage is seen more in berms and sandy dunes.

\section{Anthropogenic impacts on coastal structure deformation}

The evaluation of geometric and morphodynamic structures in western parts of Miankaleh, confirms the erosive phenomena enlargement produced by anthropogenic activities like ports construction (Fig. 3). So that shoreline has been retreated to 900 meters in this part of Miankaleh and the growing trend of erosion involves sandy dunes which caused coastal berms eradication. This event has influenced the locations of 20 kilometer radius from west direction to the east.

\section{DISCUSSION}

\section{Miankaleh territory morphology condition}

The conclusions from field observations and satellite images analysis indicated that morphologic features of Miankaleh peninsula 


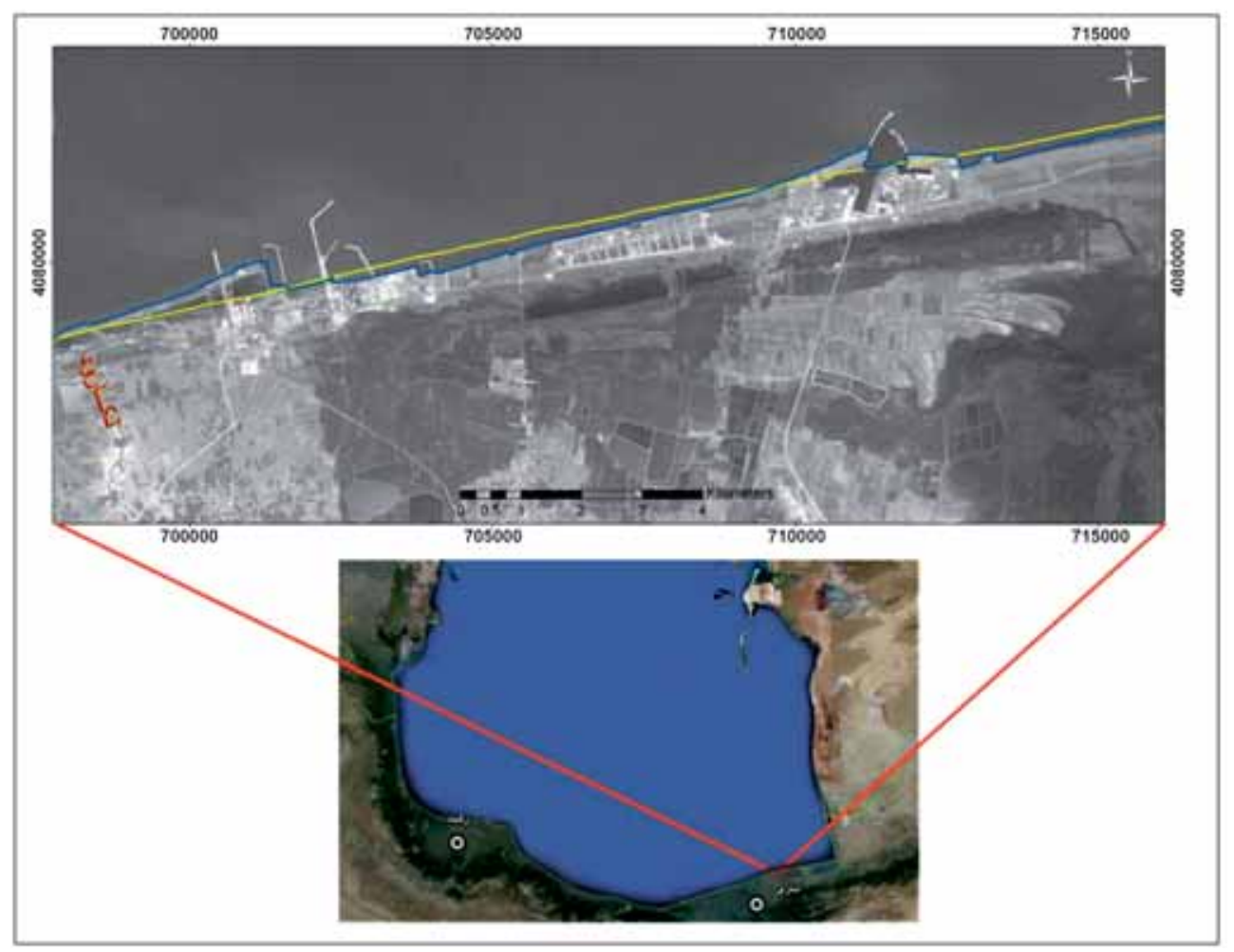

Fig. 3. Anthropogenic impact on West part of Miankaleh

have specific qualities as well as at the end eastern of Amirabad part to the central point of Tazehabad coast adjacency in Miankaleh district is formed of the Caspian primitive coastal sandy sediments. The coastal profile from Gorgan bay to the Caspian Sea shoreline orderly contains: lowland part of Gorgan bay with the dominant vegetable coverage of Xanthium shrubs and filled with calcareous shell of mollusks (bivalve and gastropod). After that we reach the primitive sandy coast of Caspian Sea with an altitude code of -24 that embraced microlithic sandy sediments and marine mussels (Cardium edule).

This part of Miankaleh territory is covered by prairie, raspberry bushes and sour pomegranate (Fig. 4). The surface of sandy sediments dressed in dark brown colored soil whose thickness is about 10 centimeters. After the wide area of primitive Caspian Sea berms, we arrive to the inactive sandy dunes which have extensive vegetative coverage. In the next area, active and semiactive sandy dunes could be seen. Ultimately, the coastal profile leads to a slight sloped beam which has reversed slope towards coastal berm along Caspian Sea shoreline with the coverage of halophytes such as Xantium plants.

This kind of biomorphological state exists in whole of western parts of Miankaleh. In fact, the morphological feature assessment of western parts of Miankaleh shows the function of Caspian Sea water level rise excessive phases in the past whose altitude code is changed of $-24 \mathrm{~m}$ to present $-26.5 \mathrm{~m}$.

Coming a large amount of sandy sediments out of sea surface, is the cause of sandy dunes formation. The widthwise expanding of sandy dunes territory is strongly related to the vegetative coverage enlargement. Due to reduction of sandy sedimentary substances, coastal berms deform to marginal wetlands in central parts of Miankaleh coast. Faraway from shoreline, sand spits are formed by coast paralleled flows in west direction to 

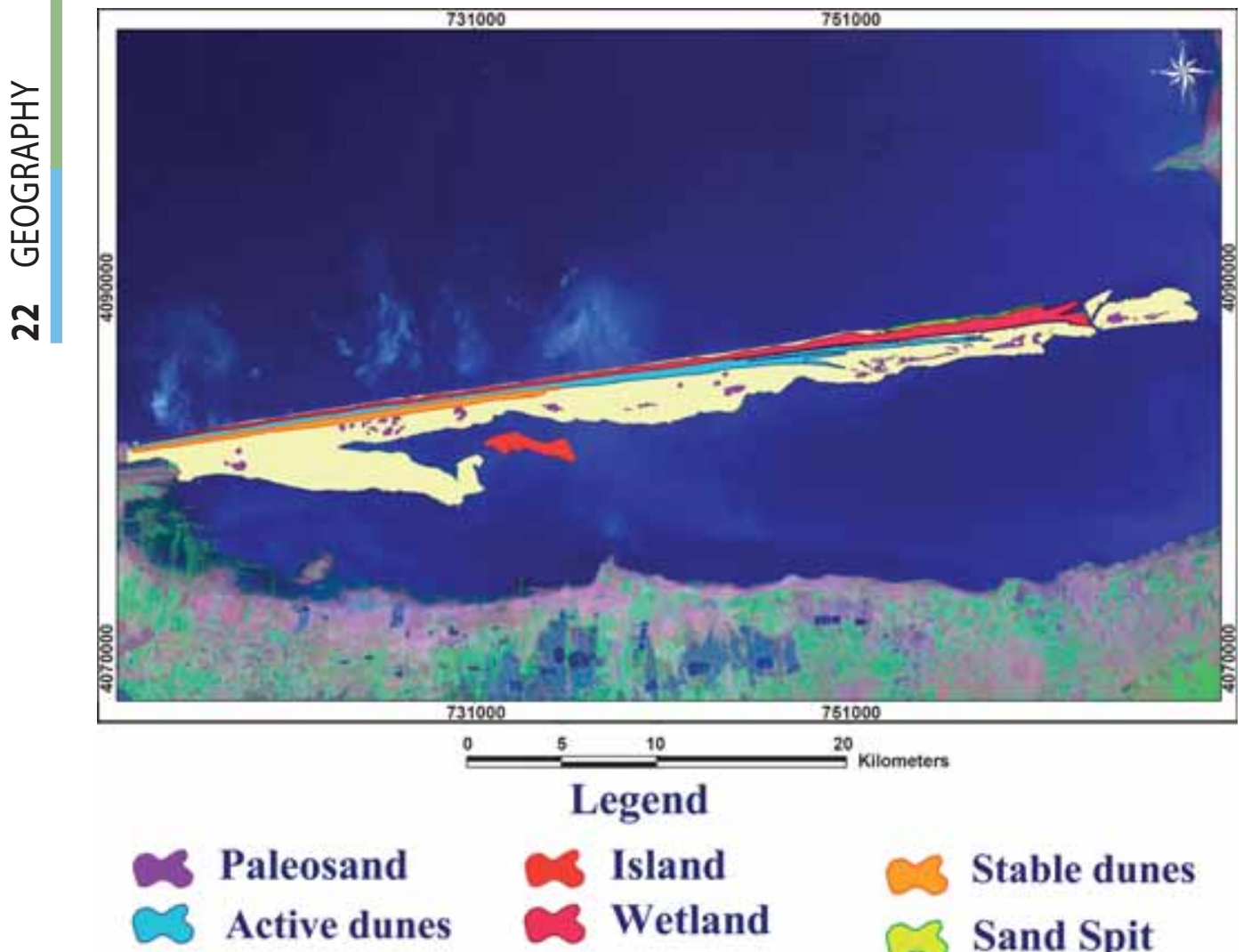

Stable dunes

Sand Spit

Fig. 4. Morphological subunits of Miankaleh territory

the east (Fig. 5). At the back of these sand spits, strip wetlands have been created with the average depth of 1.5 meters. The accumulation of vegetative coverage and the permeability of coastal lands in this area have been caused the decrease and dispersion of sandy dunes in Caspian Sea primitive coast. On the other hand, marginal basins such as wetland appear strongly in eastern slight sloped parts, while coastal sands have been disappeared. Submergence situation of this part of Miankaleh coast has been so fragile that a vast part of this area has sunk since 1978 when Caspian Sea water level has increased 2.5 meters up to now. Consequently, Khozeiny canal and aquatic
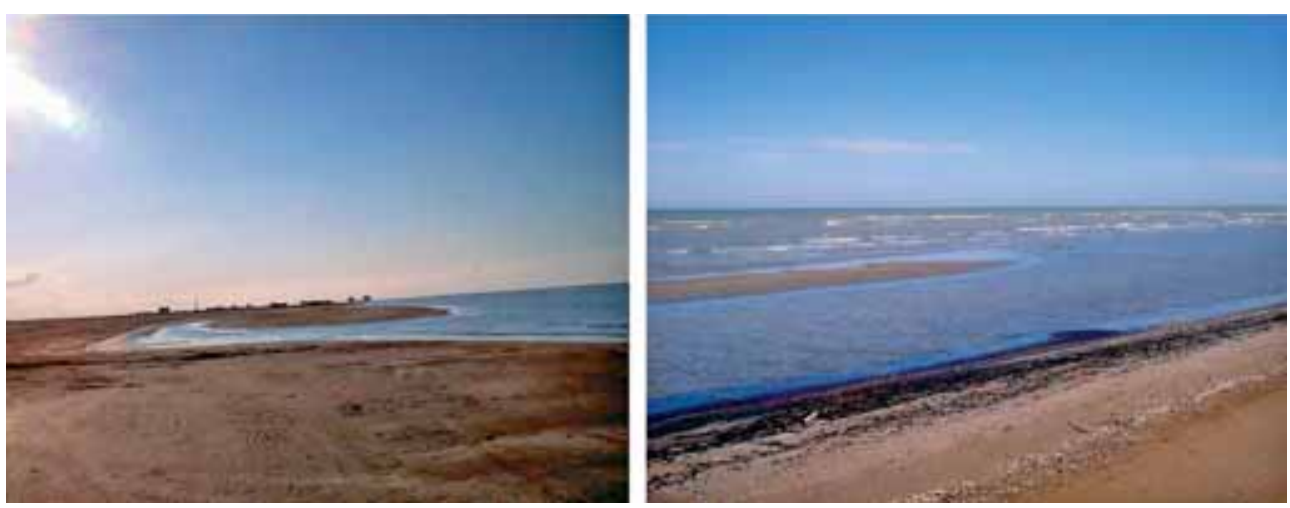

Fig. 5. Sand spit generation in the central part of Miankaleh 
connection width between Gorgan bay and Caspian Sea has been developed. One of the morphodynamic features of this area is the creation of erosive bays in south-eastern part of Miankaleh. The penetration of sea brine is the cause of salty land generation in lowland around Gorgan bay. Salty crystals appear in the mentioned salty lands at aridity time. Therefore Miankaleh contains three morphological subunits, including beach, transition zone and lagoon, in direction of west to east. And the flood vulnerability is increasing from west to east. So Ashoradeh peninsula is the most vital region to rapid sea level changing impact.

\section{Comparing of the aerial photos analysis results}

The comparing results of aerial photos processing during 40 years (1965-2005) which include two important Caspian Sea water level rise and down phases, prove deformation manner of Miankaleh district related to Caspian rapid Sea level changing. The collected data from limnograph stations show about 3 meters depression in sea water level from 1940 to 1979, whereas; Caspian Sea water level has got a rapid rise about 2.5 meters from 1979 to present. The examination of morphodynamic deformation rate in Miankaleh coast indicates that erosive vulnerability mostly exists close to the eastern regions between Torkaman port and Ashooradeh in the mentioned times. The slight slope of this region helps speed rate of marining and generally morphological features have been changed seriously as connecting canals (Khozeiny) and wetlands widthwise have been developed.

Shoreline morphodynamic deformation rate is more expanded in eastern parts in compare of western parts in as much as the shoreline has moved only 60 meters up to now. In consequence, marining is seen fewer in western parts. In the case of sea level regression, raspberry bush lands and sour pomegranate shrubs are expanded through the berm, however; owing to the water level rise and soil salinization, the mentioned vegetative coverage are destroyed and the bodies can be found under sediments. Meanwhile; it is proven that the most Vulnerability towards sea water level rise seems from the end of eastern to central part of Miankaleh peninsula. Other regions have lesser vulnerability risk.

\section{Anthropogenic impacts on erosive vulnerability}

Port constructions, groins building, coastal break water obstacles, coastal guard constructions, land surfacing and sand takings, increase erosive Vulnerability in western parts of Miankaleh close to the multipurpose Amirabad port. Actually Amirabad port (in the end western part) and Ashooradeh peninsula (in the eastern part) are affected more by anthropogenic activities. In addition; erosion phenomena has been seen more in Amirabad free zone in compare of eastern parts of Miankaleh. The rest area of Miankaleh is under protection with no human access and damages. The measurements of geometrical structure in western coast of Miankaleh indicate that quay and coastal break water obstacles induce radically berm deformation and shoreline strike deviations. There is sedimentary accumulation in west of Neka power plant. To the west, the affection of coastal flows causes coastal disruption and erosion of central parts. The main morphodynamic features, which have been obtained from human activities, are known as appearance of vast erosive terraces, developed crescent beach cusps and disappearance of berm and sandy dunes. Dramatically the effect of constructions on coast is reduced by going far from central part. Actually the impact of marine constructions is caused the movement of shoreline about 900 meters exactly in central regions (Fig. 3). Therefore; the western coast of Miankaleh is vulnerable and dangerous in view point of anthropogenic activity expansion. Finally; because of gentle slope in littoral zone which generated by coastal break water obstacles and quay, provide artificial condition of coastal land submergence. 


\section{CONCLUSIONS}

The morphological subunits and shoreline position of Miankaleh accumulative form have been recognized by comparing and processing of aerial photos related to 2 periods of expanded Caspian Sea level fluctuation(1966-2005). The observational works and surface geology have been done along the eight transects from extremity of western to eastern of mentioned area. Main results show the tendency of flooding vulnerability and shoreline displacement increase at the end of eastern region of Miankaleh near Ashooradeh peninsula where there is an interaction with Caspian rapid sea level changing. In the direction of west, shoreline deformation degree declines gradually.

\section{REFERENCES}

Khoshravan, H. (1995). Caspian sea Quaternary sediments biostratigraphy and paleogeography, Esfahan University, Academic thesis, 357 p.

Khoshravan, H. (2000). Morphological zone of the southern coasts of Caspian Sea, National research center of the Caspian Sea, internal report, 156 p.

Khoshravan, H. (2002). Miankaleh sand spit evolution reconstructing, National research center of the Caspian Sea, internal report, 114 p.

Kosari, K. (1995). Caspian Sea east- southern coasts shoreline displacement study, Geology survey of Iran, internal report, $56 \mathrm{p}$.

Moghadam, M. (2004). contamination resources management by use GIS, Bandarabbas Azad University, Academic thesis, 187 p.



Homayoun Khoshravan was born in Esfahan, Iran, in 1967. Hestudied Geology science at the Azad UniversityTtechnology and Science campus of Tehran, graduated in 1999 and obtained the PhD degree (Diploma). Since March 1993 he is a research assistant (Professor) of the Institute of Water Research WRI. The focus of his research lies in the environment, stratigraphy,morphodynamic and marine geology.

Main publications - Coastal modification impacts on the Caspian rapid sea level changing; Caspian Sea Geotechnical instability hazard assessment with use GIS; The Caspian Sea Southern Coasts contamination resources; Vulnerability and Hazardous Degree Assessment with GIS Modeling. 